Research Square

\title{
Effects of Sarcopenia and Sarcopenic Obesity on Joint Pain and Degenerative Osteoarthritis in Postmenopausal Women
}

\author{
Hye In Kim \\ Yonsei University College of Medicine \\ So Hyun Ahn \\ Yonsei University College of Medicine \\ Yup Kim \\ Yonsei University College of Medicine \\ Ji Eun Lee \\ Yonsei University College of Medicine \\ Seok Kyo Seo ( $\square$ tudeolseo@yuhs.ac) \\ Yonsei University College of Medicine
}

\section{Research Article}

Keywords: Sarcopenia, Sarcopenic obesity, Osteoarthritis, Joint pain, Hormone therapy

Posted Date: December 28th, 2021

DOI: https://doi.org/10.21203/rs.3.rs-1155240/v1

License: (c) (i) This work is licensed under a Creative Commons Attribution 4.0 International License. Read Full License 


\section{Abstract}

This study aimed to identify the prevalence of sarcopenia, obesity, and sarcopenic obesity and examine their association with radiographic knee osteoarthritis $(\mathrm{OA})$ and knee pain in Korean menopausal women.

This cross-sectional study utilized the data from Korean National Health and Nutrition Examination Surveys 2009-2011. The participants were categorized based on body composition. The prevalence of radiographic knee OA and knee pain was calculated. The effect of hormone therapy (HT) was also evaluated.

The prevalence of radiographic knee OA, knee pain, and both were all highest in the sarcopenic obese group and lowest in the non-sarcopenic nonobese group. Without sarcopenia, obese women showed higher ratio of radiographic knee OA. With sarcopenia, the coexistence of obesity presented higher ratio of radiographic knee OA, knee pain, and both compared to sarcopenia without obesity. The use of HT for more than one year was not associated with radiographic knee OA, knee pain, or both.

Obesity with sarcopenia had greater effect on knee OA compared to obesity without sarcopenia. Moreover, HT use for more than one year was not associated with the prevalence of knee OA. Therefore, more efforts should focus on reducing body fat and increasing muscle in postmenopausal women with knee OA.

\section{Introduction}

Osteoarthritis $(\mathrm{OA})$ is a common disease in the elderly population, affecting approximately 27 million adults in the United States ${ }^{1}$. OA often requires surgical treatment owing to pain and mobility restriction, and the social cost is high due to high postoperative morbidity ${ }^{2}$. Therefore, it is important to clarify the pathophysiology and reduce risk factors. OA and its various risk factors have been extensively studied in the general elderly population; however, studies in menopausal women are limited.

Menopause is a life event that greatly affects women through hormonal changes. The most well-known menopausal symptoms include vasomotor symptoms including hot flushes, atrophic vaginitis, psychological symptoms including depression, and cardiovascular symptoms ${ }^{3}$. Furthermore, temporomandibular joint disease, osteoporosis, and sarcopenic obesity have a significantly higher incidence in women than in men, suggesting a relationship between female hormones and these musculoskeletal ailments ${ }^{4-6}$. In addition, a change in hormonal status, especially a decrease in sex hormone levels, alters the body composition ${ }^{7}$. A decrease in bone mass density leads to osteoporosis. As body fat increases, the rate of obesity in menopausal women increases, and as muscle mass decreases, the rate of sarcopenia increases ${ }^{8}$. All these changes lead to a restricted life in postmenopausal women ${ }^{9}$.

Therefore, it is necessary to examine the relationship between body composition and OA in postmenopausal women. Previous studies primarily focused on the association between obesity and OA. Furthermore, the research was conducted based on anthropometric measures such as weight and BMI. However, BMI does not reflect body composition as do body fat mass and muscle mass ${ }^{10,11}$. Sarcopenia, which is characterized by a decrease in muscle mass, is a part of normal aging process but it results in functional impairment ${ }^{12}$. In menopausal women, it is rather necessary to utilize objective measures for high fat mass and relatively low muscle mass to study obesity as well as sarcopenia and sarcopenic obesity in relation to $\mathrm{OA}^{13}$.

Because low muscle mass may be owing to a deprivation of sex hormone levels in menopausal women, estrogen supplementation or hormone therapy $(\mathrm{HT})$ is used to relieve various symptoms and to protect muscle mass and muscle strength ${ }^{14,15}$; however, a few studies showed that $\mathrm{HT}$ did not show positive effect on muscle mass ${ }^{16,17}$. Furthermore, the effect of HT on knee OA is controversial; although some observational studies showed positive effect of HT on knee OA ${ }^{18,19}$, others showed no association of sex hormone replacement or knee arthroplasty 20 .

Therefore, this study aimed to identify the prevalence of sarcopenia, obesity, and sarcopenic obesity and examine their association with knee OA in Korean menopausal women and also the effect of HT using data obtained during the 2009-2011 Korean National Health and Nutrition Examination Surveys (KNHANES).

\section{Methods}

\subsection{Study design and setting}

This was a nationwide cross-sectional observational study. Data were extracted from the KNHANES conducted from 2009 to 201121 . KNHANES is a national, population-based cross-sectional survey that collects data on the health and nutrition status of Koreans by sampling representative, noninstitutionalized Korean civilians. Every year, approximately 10,000 individuals were sampled. The survey is composed of health interviews, physical examinations, and nutrition surveys. All the components of the survey were conducted either at the mobile screening center or at the home of participants by trained medical staff, dieticians, health interviewers, and medical technicians. All participants provided written informed consent. The KNHANES were performed in accordance with the principles of the Declaration of Helsinki. For this study, we used the data from 2009 to 2011 ; 
the study was approved by the institutional review board of the Korea Centre for Disease Control and Prevention (2009-01CON-03-2C, 2010-02CON21-C, 2011-02CON-06C).

\subsection{Participants}

For KNHANES from 2009 to 2011, 28,009 individuals were enrolled. Of the participants, 4,362 women were menopausal. We included only the participants who completed health interviews for sarcopenia, physical examination for BMI, knee joint radiography, and dual-energy X-ray absorptiometry (DXA). The exclusion criteria included diagnosis of surgical menopause, thyroid disease, end-stage renal disease, malignant tumor, or arthritis other than $\mathrm{OA}$ and missing variables for analysis. For sub-cohort analysis, we excluded women who did not respond to the questions regarding hormone replacement therapy (HRT). The participants were asked about the experience of HRT and the period of use in months. For this study, 4,099 women were included in the final analysis and divided into 3,952 women who had never used or had used HRT less than 12 months and the other 147 women who had used HRT for longer than 12 months for the sub-cohort analysis.

\subsection{Definition of sarcopenia and obesity}

Appendicular skeletal muscle (ASM) was defined as the sum of muscle mass in four limbs as measured by DXA (QDR 4500A; Hologic Inc., Bedford, MA). For the definition of sarcopenia, there is no single standardized diagnostic criterion. Based on a previous study that studied for sarcopenia and sarcopenic obesity using the KNHANES from 2010 to 2011, we used the value obtained by dividing ASM by body weight multiplied by 100 as the ASM index (\%). Sarcopenia was defined as two standard deviations below the mean of the same gender, young standard group and the cutoff value was $23.0 \%$ for Korean women ${ }^{22}$. Obesity was defined as body mass index $\left(\mathrm{BMI}, \mathrm{kg} / \mathrm{m}^{2}\right)$ more than or equal to 25.0 according to the guideline for the management of obesity in Korea ${ }^{23}$.

\subsection{Measurements of variables}

Current age, age at menarche and menopause, body mass index (BMI), past history of hypertension (HTN), diabetes mellitus (DM), osteoporosis, lifestyle such as alcohol consumption and smoking status, HT, and lipid profile were considered as confounding variables.

All participants completed the physical examination and blood sampling either at the mobile screening center or at home. They wore light clothing without shoes while measuring the height, weight, and blood pressure. BMI was calculated from the measured height and weight. Blood sampling was done after overnight fasting of at least $8 \mathrm{~h}$ and the samples were analyzed on the same day (Neodin Medical Institute, Seoul, South Korea).

All participants completed the standardized questionnaire regarding their medical history and lifestyle. For medical history, prior to doctor's diagnosis of HTN, DM, and osteoporosis were asked. For alcohol consumption, any previous experience was asked. A heavy drinker was defined as he/she who consumed more than $30 \mathrm{~g}$ of alcohol per day. For smoking, the participants were asked of any previous experience of smoking and the current status of smoking. Regular exercise was defined as walking for $30 \mathrm{~min}$ or more at a time, $5 \mathrm{~d}$ per week or more and muscle-strengthening exercise as anaerobic exercises such as push-ups, sit-ups, dumbbells, and barbells at least once a week. Regarding HT, the history of drug use was asked. The duration was measured in months. If they had used HT for less than a year, they were assigned to sub-cohort 1, and if they had used HT for longer than a year, they were assigned to sub-cohort 2.

Knee radiography was performed for all participants and the results were analyzed based on the Kellgren-Lawrence (KL) Scale that assesses the severity of knee OA. A grade higher than or equal to 2 was considered as radiographic knee OA. In addition, knee pain was asked on the questionnaire as knee pain for $30 \mathrm{~d}$ over the previous three months.

\subsection{Statistical analysis}

Statistical analysis software (SAS) version 9.4 (SAS Inc., Cary, NC, USA) was used for all statistical analysis and the KNHANES data were analyzed according to the KNHANES data analysis guidelines. All analyses were two tailed, and a P-value of $<0.05$ was considered significant.

Continuous variables were analyzed by one-way ANOVA considering the complex sample design to calculate the mean and standard errors (SE). Categorical variables were represented with raw percent with SEs and comparatively tested by Rao-Scott Chi-square test.

For the sub-cohort analysis, the participants were divided based on the period of HT consumption. After adjusting for age and BMI, the continuous variable was represented with mean and SE, and analysis of covariance was applied to test statistical significance. The dichotomous variables were represented with ratio and standard deviation (SD), and logistic regression model was used to identify association.

\section{Results}

Subjects were divided into four groups based on their body composition: 1) non-sarcopenic non-obese: did not meet the definition for obesity or sarcopenia; 2) sarcopenic: met definition for sarcopenia but not obesity; 3) obese: met definition for obesity but not sarcopenia; 4) sarcopenic obese: met definition for both sarcopenia and obesity.

\subsection{Demographic characteristics of participants}

Page $3 / 11$ 
From 2009 to 2011, 28,009 people participated in KNHANES, of which 4,362 participants were menopaused. Our final cohort included 4,150 subjects after excluding those who did not complete the survey. 1,231 people were with normal body composition, 1,379 were sarcopenic but not obese, 203 were obese but not sarcopenic, and 1,337 were both sarcopenic and obese. The baseline characteristics of participants according to the body composition are presented in Table 1. 
Table 1

Baseline clinical characteristics of all subjects.

\begin{tabular}{|c|c|c|c|c|c|c|c|c|c|c|c|}
\hline & \multicolumn{2}{|c|}{ Total $(\mathrm{N}=4150)$} & \multicolumn{2}{|c|}{$\begin{array}{l}\text { Non-sarcopenic } \\
\text { non-obese } \\
(\mathrm{N}=1231)\end{array}$} & \multicolumn{2}{|c|}{$\begin{array}{l}\text { Sarcopenic } \\
(\mathrm{N}=1379)\end{array}$} & \multicolumn{2}{|c|}{ Obese $(\mathrm{N}=203)$} & \multicolumn{2}{|c|}{$\begin{array}{l}\text { Sarcopenic obese } \\
(\mathrm{N}=1337)\end{array}$} & \multirow[t]{2}{*}{$\begin{array}{l}\text { P- } \\
\text { value }\end{array}$} \\
\hline & $\begin{array}{l}\text { Mean } \\
\text { or } \\
\text { Row } \\
\text { percent }\end{array}$ & $\begin{array}{l}\text { Standard } \\
\text { error }\end{array}$ & $\begin{array}{l}\text { Mean } \\
\text { or } \\
\text { Row } \\
\text { percent }\end{array}$ & $\begin{array}{l}\text { Standard } \\
\text { error }\end{array}$ & $\begin{array}{l}\text { Mean } \\
\text { or } \\
\text { Row } \\
\text { percent }\end{array}$ & $\begin{array}{l}\text { Standard } \\
\text { error }\end{array}$ & $\begin{array}{l}\text { Mean } \\
\text { or } \\
\text { Row } \\
\text { percent }\end{array}$ & $\begin{array}{l}\text { Standard } \\
\text { error }\end{array}$ & $\begin{array}{l}\text { Mean } \\
\text { or } \\
\text { Row } \\
\text { percent }\end{array}$ & $\begin{array}{l}\text { Standard } \\
\text { error }\end{array}$ & \\
\hline Age (year) & 62.41 & 0.25 & 62.79 & 0.49 & 62.20 & 0.41 & 60.20 & 1.04 & 62.60 & 0.36 & 0.098 \\
\hline $\begin{array}{l}\text { Age at menopause } \\
\text { (year) }\end{array}$ & 48.40 & 0.12 & 47.80 & 0.25 & 48.54 & 0.21 & 47.93 & 0.63 & 48.84 & 0.21 & 0.012 \\
\hline $\begin{array}{l}\text { Age at menarche } \\
\text { (year) }\end{array}$ & 13.96 & 0.28 & 14.69 & 0.51 & 13.78 & 0.51 & 12.53 & 0.97 & 13.71 & 0.38 & 0.152 \\
\hline Height (cm) & 153.47 & 0.14 & 153.92 & 0.30 & 153.38 & 0.23 & 154.17 & 0.63 & 153.05 & 0.20 & 0.066 \\
\hline Weight (kg) & 57.15 & 0.18 & 51.40 & 0.28 & 53.91 & 0.20 & 62.98 & 0.59 & 64.91 & 0.25 & $<.001$ \\
\hline $\mathrm{BMI}(\mathrm{kg} / \mathrm{m} 2)$ & 24.23 & 0.07 & 21.64 & 0.08 & 22.88 & 0.05 & 26.45 & 0.12 & 27.67 & 0.09 & $<.001$ \\
\hline $\begin{array}{l}\text { Waist } \\
\text { circumference(cm) }\end{array}$ & 82.33 & 0.22 & 75.75 & 0.27 & 79.46 & 0.25 & 87.33 & 0.69 & 90.54 & 0.33 & $<.001$ \\
\hline ASM index (\%) & 24.65 & 0.08 & 27.64 & 0.08 & 23.60 & 0.06 & 26.65 & 0.07 & 22.77 & 0.07 & $<.001$ \\
\hline \multicolumn{12}{|l|}{ Past history } \\
\hline Hypertension & & & & & & & & & & & $<.001$ \\
\hline No & 60.10 & 1.11 & 73.25 & 1.93 & 61.23 & 1.90 & 64.79 & 5.04 & 46.53 & 2.01 & \\
\hline Yes & 39.90 & 1.11 & 26.75 & 1.93 & 38.77 & 1.90 & 35.21 & 5.04 & 53.47 & 2.01 & \\
\hline Diabetes mellitus & & & & & & & & & & & 0.001 \\
\hline No & 87.30 & 0.73 & 90.63 & 1.06 & 88.03 & 1.17 & 84.96 & 3.53 & 83.92 & 1.28 & \\
\hline Yes & 12.70 & 0.73 & 9.37 & 1.06 & 11.97 & 1.17 & 15.04 & 3.53 & 16.08 & 1.28 & \\
\hline Osteoporosis & & & & & & & & & & & 0.927 \\
\hline No & 81.40 & 0.86 & 80.59 & 1.56 & 81.58 & 1.41 & 82.59 & 3.34 & 81.76 & 1.61 & \\
\hline Yes & 18.60 & 0.86 & 19.41 & 1.56 & 18.42 & 1.41 & 17.41 & 3.34 & 18.24 & 1.61 & \\
\hline \multicolumn{12}{|l|}{ Drinking } \\
\hline $\begin{array}{l}\text { Alcohol } \\
\text { consumption }\end{array}$ & & & & & & & & & & & 0.855 \\
\hline No & 31.65 & 1.12 & 32.90 & 1.90 & 30.79 & 1.73 & 31.15 & 4.22 & 31.50 & 1.86 & \\
\hline Yes & 68.35 & 1.12 & 67.10 & 1.90 & 69.21 & 1.73 & 68.85 & 4.22 & 68.50 & 1.86 & \\
\hline $\begin{array}{l}\text { Amount of } \\
\text { alcohol/time }\end{array}$ & & & & & & & & & & & 0.227 \\
\hline Mild to moderate & 67.04 & 1.57 & 67.01 & 2.98 & 69.55 & 2.46 & 73.26 & 4.90 & 63.27 & 2.82 & \\
\hline Heavy(>30g/day) & 32.96 & 1.57 & 32.99 & 2.98 & 30.45 & 2.46 & 26.74 & 4.90 & 36.73 & 2.82 & \\
\hline \multicolumn{12}{|l|}{ Smoking } \\
\hline Smoking & & & & & & & & & & & 0.268 \\
\hline Never smoked & 90.44 & 0.74 & 88.95 & 1.23 & 89.93 & 1.29 & 91.35 & 3.15 & 92.17 & 1.06 & \\
\hline $\begin{array}{l}\text { Current/past } \\
\text { smoker }\end{array}$ & 9.56 & 0.74 & 11.05 & 1.23 & 10.07 & 1.29 & 8.65 & 3.15 & 7.83 & 1.06 & \\
\hline
\end{tabular}

Sarcopenic: ASM index $<25.6 \%$; Obese: $\mathrm{BMI} \geq 25$

BMI, body mass index; ASM, appendicular skeletal muscle mass; Wt, body weight; HT, hormone therapy 


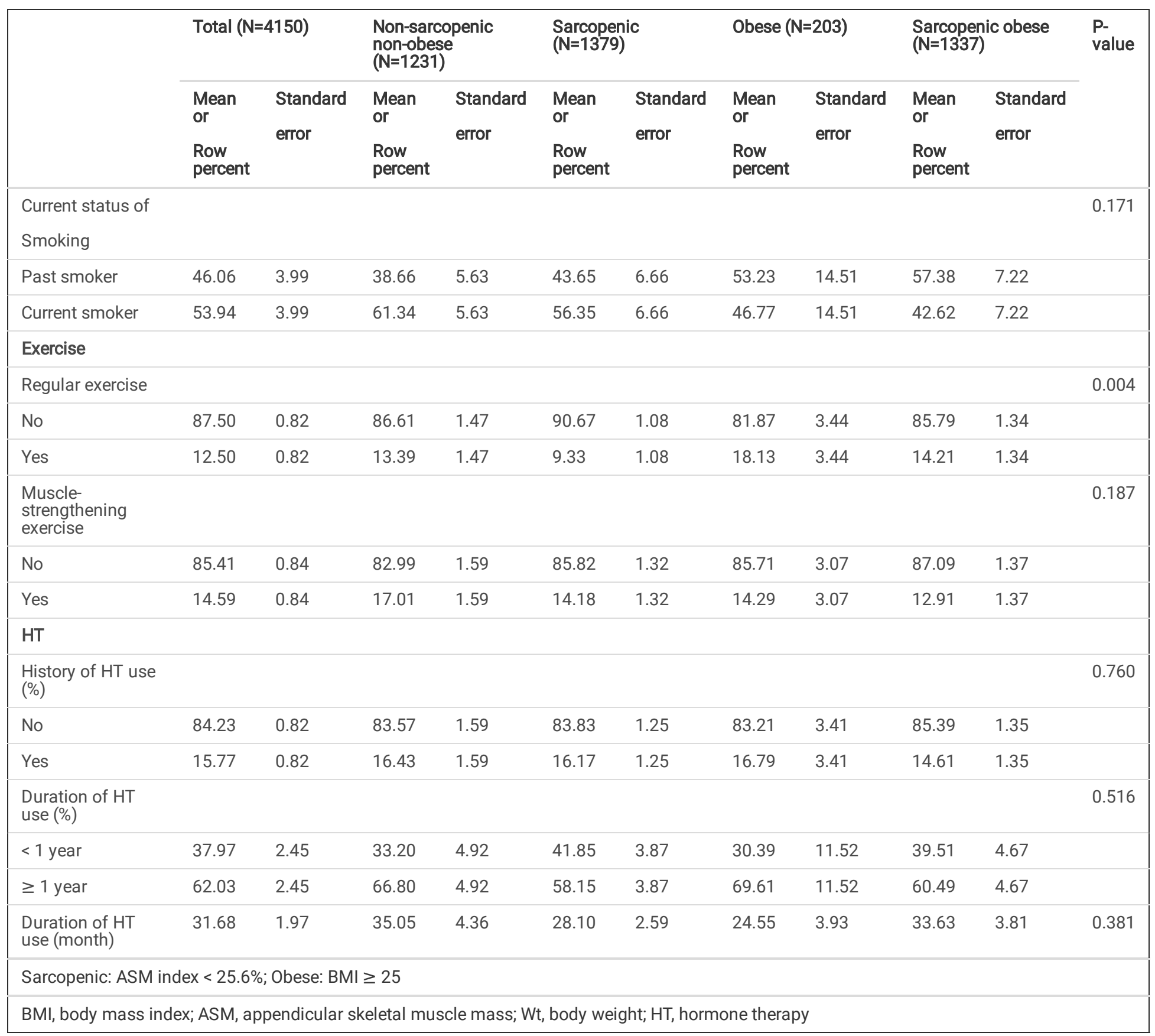

The mean age of the participants was $62.41 \pm 0.25$ years. The mean age at menopause and menarche was $48.40 \pm 0.12$ years and $13.96 \pm 0.28$ years, respectively. Only the mean age at menopause was significantly different $(p=0.012)$. The characteristics related to obesity such as weight, body mass index (BMI), and waist circumference, and ASM index presented significant difference among the four groups in the expected direction ( $\mathrm{p}<$ 0.001).

For the past history, the prevalence of HTN and DM was significantly different among the four groups with the prevalence being the highest for the sarcopenic obese group for both HTN and DM $(p<0.001)$, while that of osteoporosis was not significantly different $(p=0.927)$.

In terms of lifestyle, smoking and alcohol consumption were not significantly different among the groups. The two obese groups tended to exercise regularly more than the non-obese groups. The previous use of HT was not significantly different among the groups.

\subsection{Radiographic and clinical knee OA based on body composition}

Table 2 shows the prevalence of radiographic knee OA and knee pain of the four groups. The ratio of radiographic knee OA, knee pain, and both radiographic knee $\mathrm{OA}$ and knee pain were analyzed. There was a significant difference among the four groups in all three variables ( $p<0.001)$. 
Table 2

Prevalence of radiographic knee $\mathrm{OA}$, knee pain and both radiographic and knee pain

\begin{tabular}{|c|c|c|c|c|c|c|c|c|c|c|c|}
\hline & \multicolumn{2}{|c|}{ Total $(\mathrm{N}=4150)$} & \multicolumn{2}{|c|}{$\begin{array}{l}\text { Non-sarcopenic non- } \\
\text { obese }(\mathrm{N}=1231)\end{array}$} & \multicolumn{2}{|c|}{$\begin{array}{l}\text { Sarcopenic } \\
(\mathrm{N}=1379)\end{array}$} & \multicolumn{2}{|c|}{ Obese $(\mathrm{N}=203)$} & \multicolumn{2}{|c|}{$\begin{array}{l}\text { Sarcopenic obese } \\
(\mathrm{N}=1337)\end{array}$} & \multirow{2}{*}{$\begin{array}{l}\text { Overal } \\
\text { P- } \\
\text { value }\end{array}$} \\
\hline & $\begin{array}{l}\text { Mean } \\
\text { or } \\
\text { Row } \\
\text { percent }\end{array}$ & $\begin{array}{l}\text { Standard } \\
\text { error }\end{array}$ & $\begin{array}{l}\text { Mean or } \\
\text { Row } \\
\text { percent }\end{array}$ & $\begin{array}{l}\text { Standard } \\
\text { error }\end{array}$ & $\begin{array}{l}\text { Mean } \\
\text { or } \\
\text { Row } \\
\text { percent }\end{array}$ & $\begin{array}{l}\text { Standard } \\
\text { error }\end{array}$ & $\begin{array}{l}\text { Mean } \\
\text { or } \\
\text { Row } \\
\text { percent }\end{array}$ & $\begin{array}{l}\text { Standard } \\
\text { error }\end{array}$ & $\begin{array}{l}\text { Mean } \\
\text { or } \\
\text { Row } \\
\text { percent }\end{array}$ & $\begin{array}{l}\text { Standard } \\
\text { error }\end{array}$ & \\
\hline $\begin{array}{l}\text { Radiographic } \\
\text { knee OA }\end{array}$ & & & & & & & & & & & $<.001$ \\
\hline Yes & 48.75 & 1.18 & 41.54 & 2.10 & 41.82 & 2.09 & 57.64 & 4.99 & 61.49 & 2.01 & \\
\hline No & 51.25 & 1.18 & 58.46 & 2.10 & 58.18 & 2.09 & 42.36 & 4.99 & 38.51 & 2.01 & \\
\hline Knee pain & & & & & & & & & & & $<.001$ \\
\hline Yes & 31.41 & 1.27 & 27.55 & 2.21 & 27.61 & 1.96 & 29.91 & 5.22 & 39.11 & 2.22 & \\
\hline No & 68.59 & 1.27 & 72.45 & 2.21 & 72.39 & 1.96 & 70.09 & 5.22 & 60.89 & 2.22 & \\
\hline $\begin{array}{l}\text { Radiographic } \\
\text { knee OA \& Knee } \\
\text { pain }\end{array}$ & & & & & & & & & & & $<.001$ \\
\hline Yes & 22.70 & 1.12 & 17.82 & 1.93 & 17.60 & 1.70 & 25.96 & 5.17 & 32.04 & 2.20 & \\
\hline No & 77.30 & 1.12 & 82.18 & 1.93 & 82.40 & 1.70 & 74.04 & 5.17 & 67.96 & 2.20 & \\
\hline OA, osteoarthritis & & & & & & & & & & & \\
\hline
\end{tabular}

Table 3 shows the $p$-value as a result of multiple groupwise comparisons among the four groups. Among the non-obese people, the effect of sarcopenia can be compared by comparing non-sarcopenic non-obese group with sarcopenic group. In Table 2, the ratios of each and both radiographic $O A$ and knee pain were higher in the sarcopenic group, but there was no significant difference in all $(p=0.922,0.981$, and 0.932 , respectively). Among the obese people, the effect of sarcopenia can be presented by comparing the obese and sarcopenic obese groups. The ratios of each and both radiographic $\mathrm{OA}$ and knee pain were higher in the sarcopenic obese group, but there was no significant difference in any ( $p=0.467$, 0.118 , and 0.298 , respectively). However, among the people without sarcopenia, the obese people tended to show a higher ratio of radiographic OA significantly $(57.64 \%$ vs. $41.54 \%, p<0.001)$. Knee pain and both radiographic and clinical knee $0 A$ were not significantly different $(p=0.658$ and 0.098 , respectively). Finally, for people with sarcopenia, obesity increased the ratio of radiographic knee OA, knee pain, and both radiographic knee $\mathrm{OA}$ and knee pain. For radiographic knee OA, although the ratio was $41.82 \%$ for the sarcopenic group, that of the sarcopenic obese group was $61.49 \%$ $(p<0.001)$. The ratio of knee pain was also statistically different between the sarcopenic and sarcopenic obese groups $(27.55 \%$ and $39.11 \%$, respectively; $p$ 0.001). Lastly, the ratio of people with both radiographic knee OA and knee pain was $17.60 \%$ and $32.04 \%$ for sarcopenic and sarcopenic obese groups, respectively $(p<0.001)$.

Table 3

Multiple comparison results of the prevalence of radiographic knee OA, knee pain and both radiographic and knee pain

\begin{tabular}{|c|c|c|c|c|}
\hline & $\begin{array}{l}\text { Non-obese } \\
\text { non-sarcopenic vs. } \\
\text { sarcopenic }\end{array}$ & $\begin{array}{l}\text { Non-sarcopenic } \\
\text { non-obese vs. } \\
\text { obese }\end{array}$ & $\begin{array}{l}\text { Sarcopenic } \\
\text { non-obese vs. } \\
\text { obese }\end{array}$ & $\begin{array}{l}\text { Obese } \\
\text { non-sarcopenic vs. } \\
\text { sarcopenic }\end{array}$ \\
\hline Radiographic knee OA & 0.922 & $<.001$ & $<.001$ & 0.467 \\
\hline Knee pain & 0.981 & 0.658 & $<.001$ & 0.118 \\
\hline $\begin{array}{l}\text { Radiographic knee OA \& Knee } \\
\text { pain }\end{array}$ & 0.932 & 0.098 & $<.001$ & 0.298 \\
\hline \multicolumn{5}{|l|}{ OA, osteoarthritis } \\
\hline
\end{tabular}

\subsection{Hormone therapy}

Based on the answers to the use of HT in the questionnaire, a sub-cohort analysis was done. Among the postmenopausal women who had used HT before, 240 women used HT for less than a year, whereas the other 398 used it for longer than a year. In Table 4, the mean ASM index of these two groups did not show a significant difference $(24.47 \%$ and $24.80 \%$, respectively, $p=0.181)$. The ratio of sarcopenia showed no significant association 
with the duration of HT use $(69.80 \%$ and $62.11 \%$, respectively, $\mathrm{p}=0.147)$. For the radiographic knee OA, knee pain, and both radiographic knee OA and knee pain, none of the ratios were significant between the two groups ( $p=0.688,0.634$, and 0.649 , respectively).

Table 4

Sub-cohort analysis: Duration of HT use $<1$ year vs. HT $\geq 1$ year

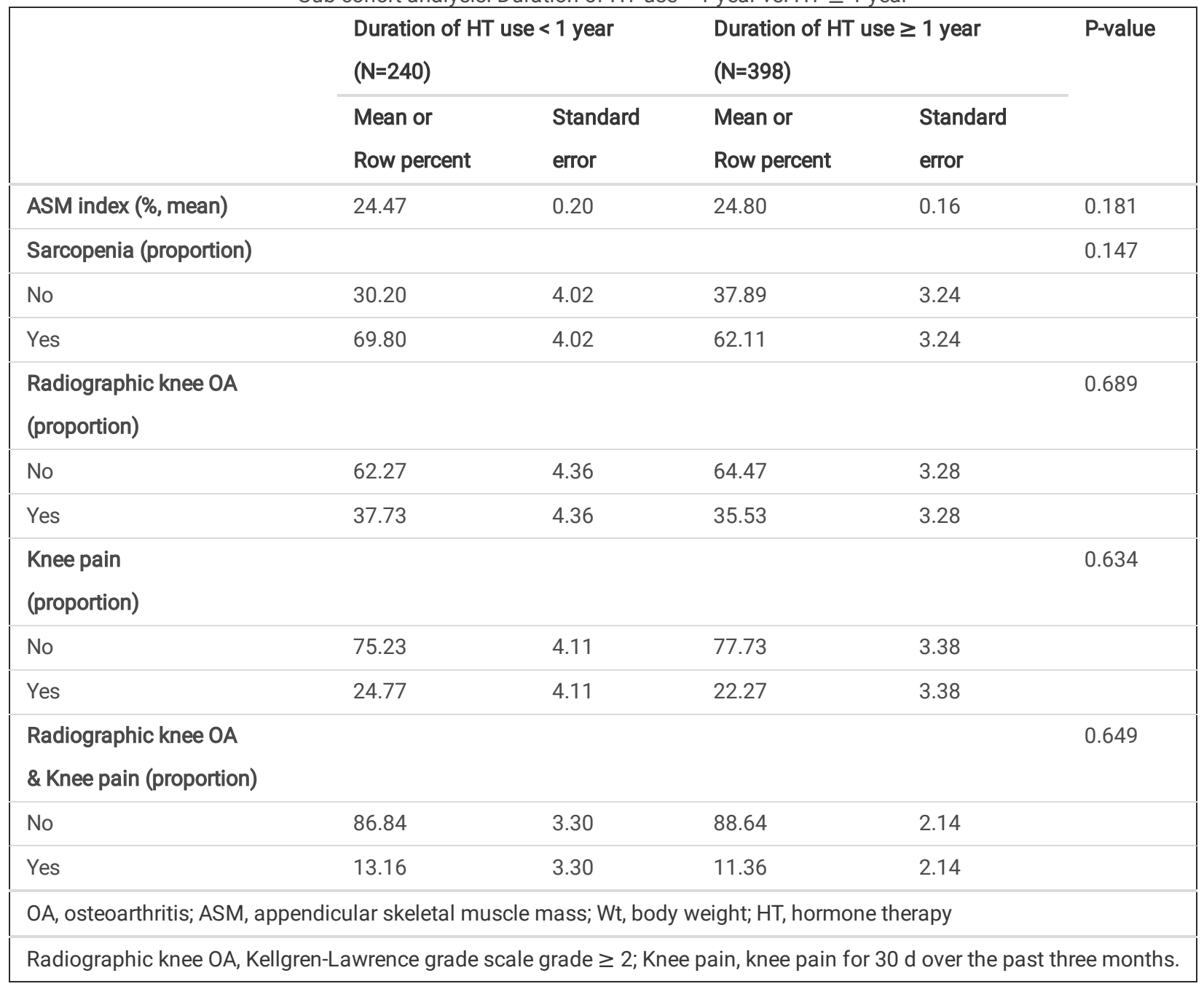

Table 5 shows the results after adjustment for age and BMI. The average ASM index was not significantly different between the two groups ( $p=$ 0.119), which was similar to the result before the adjustment. Both the ratio of sarcopenia and radiographic OA did not show a significant difference between the two groups ( $p=0.082$ and $p=0.506$, respectively). 
Table 5

Sub-cohort analysis adjusted for age and BMI

\begin{tabular}{|c|c|c|c|c|c|}
\hline & \multicolumn{2}{|c|}{$\begin{array}{l}\text { Duration of HT use }<1 \text { year } \\
(\mathrm{N}=240)\end{array}$} & \multicolumn{2}{|c|}{$\begin{array}{l}\text { Duration of HT use } \geq 1 \text { year } \\
(\mathrm{N}=398)\end{array}$} & \multirow[t]{2}{*}{ P-value* } \\
\hline & Mean or proportion* & $\begin{array}{l}\text { Standard } \\
\text { error }\end{array}$ & Mean or proportion* & $\begin{array}{l}\text { Standard } \\
\text { error }\end{array}$ & \\
\hline ASM index (\%, mean) & 24.35 & 0.18 & 24.68 & 0.15 & 0.119 \\
\hline $\begin{array}{l}\text { Sarcopenia } \\
\text { (proportion) }\end{array}$ & 0.77 & 0.05 & 0.67 & 0.08 & 0.082 \\
\hline $\begin{array}{l}\text { Radiographic knee OA } \\
\text { (proportion) }\end{array}$ & 0.44 & 0.05 & 0.4022 & 0.0362 & 0.5061 \\
\hline \multicolumn{6}{|c|}{ OA, osteoarthritis; ASM, appendicular skeletal muscle mass; $\mathrm{Wt}$, body weight; $\mathrm{HT}$, hormone therapy } \\
\hline \multicolumn{6}{|c|}{ Radiographic knee OA, Kellgren-Lawrence grade scale grade $\geq 2$} \\
\hline
\end{tabular}

\section{Discussion}

Menopause, which involves a drastic change in hormonal status and results in a decrease in sex hormone levels, has a great effect on bone mass density and body fat distribution ${ }^{7}$. A decrease in bone mass density can lead to osteoporosis, an increase in body fat to obesity, and a decrease in body muscle to sarcopenia, which are all closely related to knee OA in menopausal women. Additionally, HT after menopause, which keeps the estradiol level enough to relieve menopausal symptoms, is considered to be helpful in preventing knee OA ${ }^{18}$.

Although the association between knee $\mathrm{OA}$ and anthropometric measures such as BMI and weight have been studied well, there are few studies regarding the association of body composition with knee OA in literature. However, the results of the studies were not in the same trend because of their different study design, participants, measurement of body composition, and definition of obesity ${ }^{13,24-26}$. The longitudinal study conducted by Misra et al. showed that the risk of knee OA was increased in sarcopenic obese people, especially in women with statistical significance ${ }^{26}$. However, another study showed that body weight and BMI were more important factors associated with knee OA compared to body composition such as fat distribution or muscle mass as measured by DXA ${ }^{13}$. In a study by Suh et al that also utilized data from KNHANES, obese people with low muscle mass, who were sarcopenic obese, presented greater odds of radiographic knee OA compared to the non-sarcopenic non-obese people, whereas obese people without low muscle mass showed no increased odds ${ }^{25}$.

This is the first cross-sectional study with a large number to present the association between knee OA and body composition acquired with DXA such as sarcopenia and sarcopenic obesity. Based on the body composition analyzed with DXA, the participants were categorized into four categories. For people without sarcopenia, the status of obesity only affected the prevalence of radiographic knee OA. However, for people with sarcopenia, the status of obesity affected the prevalence of not only radiographic knee OA but also knee pain. This emphasizes the fact that obesity may have more effect only when sarcopenia coexists, suggesting that the risk of knee OA in menopausal women is through both high muscle mass and low muscle mass, not just one. The contrasting results of a previous study by Misra et al. can be explained by the fact that Misra et al. included both sexes in their study, whereas we analyzed only menopausal women ${ }^{26}$.

HT is used by menopausal women to relieve various menopausal symptoms such as hot flushes. HT affects not only the vasomotor symptoms but also the prevalence of $\mathrm{OA}^{19}$. Cirillo et al. showed that neither estrogen replacement nor estrogen plus progestogen therapy affected the need for knee joint replacement ${ }^{27}$. Our study also included a sub-cohort analysis to see the long-term effect of HT and we divided the participants based on the use of HT for longer than a year ${ }^{28}$. Different from the studies that presented that HT relieved both the prevalence of radiographic knee OA and knee pain, our results showed no statistical significance in comparison based on $\mathrm{HT}^{29,30}$. Confounding factors such as duration, dose, type of $\mathrm{HT}$ used, lifestyle, and daily activity could explain the discordant results.

This study has some strengths. First, this study utilized the standardized nationwide data with a great number of participants. Second, to see the effect of sarcopenia and obesity in relation to each other, we categorized the participants into four groups and performed group-to-group multiple comparisons. Third, considering the specificity of the participants, we also conducted a sub-cohort analysis to see the effects of HT on both clinical and radiological knee $O A$.

However, this study has several limitations. First, the results of this comparative, cross-sectional study design cannot be interpreted as a causal relationship between body composition and knee OA. Second, the variables obtained by self-questionnaire are subject to information bias or recall 
bias. Third, the type of HT was not analyzed due to the lack of data. Further prospective studies with a large number of subjects are required for a more detailed explanation regarding the relationship between sarcopenic obesity and knee OA.

In conclusion, obesity in terms of sarcopenia has greater effect on knee OA compared to obesity without sarcopenia. Moreover, HT use of longer than a year is not associated with the prevalence of knee OA. Therefore, in knee OA, more preventive efforts should focus on reducing body fat and increasing muscle in postmenopausal women.

\section{Declarations}

\section{Acknowledgements}

We would like to thank members of the Department of Obstetrics and Gynecology, Yonsei University College of Medicine for their generous support of this research.

\section{Author Contributions}

HIK: conceptualization, methodology and investigation, writing-original draft preparation, visualization; SHA: methodology and investigation, Visualization; YK: formal analysis, data curation; JEL: formal analysis; SSK: conceptualization, supervision, project administration.

\section{Data statement}

The datasets used and/or analyzed during the current study are available from the corresponding author on reasonable request.

\section{Ethics Statement}

All participants provided written informed consent. The KNHANES were performed in accordance with the principles of the Declaration of Helsinki. The study was approved by the institutional review board of the Korea Centre for Disease Control and Prevention (2009-01CON-03-2C, 2010-02CON21-C, 2011-02CON-06C).

\section{Conflict of Interest}

Hye In Kim, So Hyun Ahn, Yup Kim, Ji Eun Lee, and Seok Kyo Seo declare no competing interests.

\section{References}

1. Lawrence, R. C. et al. Estimates of the prevalence of arthritis and other rheumatic conditions in the United States. Part II. Arthritis Rheum 58, 2635, doi:10.1002/art.23176 (2008).

2. Singh, J. A., Kwoh, C. K., Richardson, D., Chen, W. \& Ibrahim, S. A. Sex and surgical outcomes and mortality after primary total knee arthroplasty: a risk-adjusted analysis. Arthritis Care Res (Hoboken) 65, 1095-1102, doi:10.1002/acr.21953 (2013).

3. Nelson, H. D. Menopause. Lancet 371, 760-770, doi:10.1016/S0140-6736(08)60346-3 (2008).

4. Abellan van Kan, G. Epidemiology and consequences of sarcopenia. J Nutr Health Aging 13, 708-712, doi:10.1007/s12603-009-0201-z (2009).

5. Bagis, B., Ayaz, E. A., Turgut, S., Durkan, R. \& Ozcan, M. Gender difference in prevalence of signs and symptoms of temporomandibular joint disorders: a retrospective study on 243 consecutive patients. Int J Med Sci 9, 539-544, doi:10.7150/ijms.4474 (2012).

6. O'Connor, M. I. Sex differences in osteoarthritis of the hip and knee. J Am Acad Orthop Surg 15 Suppl 1, S22-25 (2007).

7. Carr, M. C. The emergence of the metabolic syndrome with menopause. J Clin Endocrinol Metab 88, 2404-2411, doi:10.1210/jc.2003-030242 (2003).

8. Cruz-Jentoft, A. J. et al. Sarcopenia: European consensus on definition and diagnosis: Report of the European Working Group on Sarcopenia in Older People. Age Ageing 39, 412-423, doi:10.1093/ageing/afq034 (2010).

9. Riis, B. J., Hansen, M. A., Jensen, A. M., Overgaard, K. \& Christiansen, C. Low bone mass and fast rate of bone loss at menopause: equal risk factors for future fracture: a 15-year follow-up study. Bone 19, 9-12, doi:10.1016/8756-3282(96)00102-0 (1996).

10. Felson, D. T., Anderson, J. J., Naimark, A., Walker, A. M. \& Meenan, R. F. Obesity and knee osteoarthritis. The Framingham Study. Ann Intern Med 109, 18-24, doi:10.7326/0003-4819-109-1-18 (1988).

11. Grotle, M., Hagen, K. B., Natvig, B., Dahl, F. A. \& Kvien, T. K. Obesity and osteoarthritis in knee, hip and/or hand: an epidemiological study in the general population with 10 years follow-up. BMC Musculoskelet Disord 9, 132, doi:10.1186/1471-2474-9-132 (2008).

12. Janssen, I., Heymsfield, S. B. \& Ross, R. Low relative skeletal muscle mass (sarcopenia) in older persons is associated with functional impairment and physical disability. J Am Geriatr Soc 50, 889-896, doi:10.1046/j.1532-5415.2002.50216.x (2002).

13. Abbate, L. M. et al. Anthropometric measures, body composition, body fat distribution, and knee osteoarthritis in women. Obesity (Silver Spring) 14, 1274-1281, doi:10.1038/oby.2006.145 (2006). 
14. Chen, Z. et al. Postmenopausal hormone therapy and body composition--a substudy of the estrogen plus progestin trial of the Women's Health Initiative. Am J Clin Nutr 82, 651-656, doi:10.1093/ajcn.82.3.651 (2005).

15. Kim, S. W. \& Kim, R. The association between hormone therapy and sarcopenia in postmenopausal women: the Korea National Health and Nutrition Examination Survey, 2008-2011. Menopause 27, 506-511, doi:10.1097/GME.0000000000001509 (2020).

16. Hansen, R. D., Raja, C., Baber, R. J., Lieberman, D. \& Allen, B. J. Effects of 20-mg oestradiol implant therapy on bone mineral density, fat distribution and muscle mass in postmenopausal women. Acta Diabeto/ 40 Suppl 1, S191-195, doi:10.1007/s00592-003-0063-5 (2003).

17. Kenny, A. M., Dawson, L., Kleppinger, A., lannuzzi-Sucich, M. \& Judge, J. O. Prevalence of sarcopenia and predictors of skeletal muscle mass in nonobese women who are long-term users of estrogen-replacement therapy. J Gerontol A Biol Sci Med Sci 58, M436-440, doi:10.1093/gerona/58.5.m436 (2003).

18. Jung, J. H. et al. Knee osteoarthritis and menopausal hormone therapy in postmenopausal women: a nationwide cross-sectional study. Menopause 26, 598-602, doi:10.1097/GME.0000000000001280 (2018).

19. Spector, T. D., Nandra, D., Hart, D. J. \& Doyle, D. V. Is hormone replacement therapy protective for hand and knee osteoarthritis in women?: The Chingford Study. Ann Rheum Dis 56, 432-434, doi:10.1136/ard.56.7.432 (1997).

20. Hussain, S. M. et al. Incidence of total knee and hip replacement for osteoarthritis in relation to circulating sex steroid hormone concentrations in women. Arthritis Rheumatol 66, 2144-2151, doi:10.1002/art.38651 (2014).

21. Kweon, S. et al. Data resource profile: the Korea National Health and Nutrition Examination Survey (KNHANES). Int J Epidemio/ 43, 69-77, doi:10.1093/ije/dyt228 (2014).

22. Kim, Y. S. et al. Prevalence of sarcopenia and sarcopenic obesity in the Korean population based on the Fourth Korean National Health and Nutritional Examination Surveys. J Gerontol A Biol Sci Med Sci 67, 1107-1113, doi:10.1093/gerona/gls071 (2012).

23. Seo, M. H. et al. 2018 Korean Society for the Study of Obesity Guideline for the Management of Obesity in Korea. J Obes Metab Syndr 28, 40-45, doi:10.7570/jomes.2019.28.1.40 (2019).

24. Lee, S., Kim, T. N. \& Kim, S. H. Sarcopenic obesity is more closely associated with knee osteoarthritis than is nonsarcopenic obesity: a crosssectional study. Arthritis Rheum 64, 3947-3954, doi:10.1002/art.37696 (2012).

25. Suh, D. H. et al. Body composition is more closely related to the development of knee osteoarthritis in women than men: a cross-sectional study using the Fifth Korea National Health and Nutrition Examination Survey (KNHANES V-1, 2). Osteoarthritis Cartilage 24, 605-611, doi:10.1016/j.joca.2015.10.011 (2016).

26. Misra, D. et al. Risk of Knee Osteoarthritis With Obesity, Sarcopenic Obesity, and Sarcopenia. Arthritis Rheumatol 71, 232-237, doi:10.1002/art.40692 (2019).

27. Cirillo, D. J., Wallace, R. B., Wu, L. \& Yood, R. A. Effect of hormone therapy on risk of hip and knee joint replacement in the Women's Health Initiative. Arthritis Rheum 54, 3194-3204, doi:10.1002/art.22138 (2006).

28. Marjoribanks, J., Farquhar, C., Roberts, H., Lethaby, A. \& Lee, J. Long-term hormone therapy for perimenopausal and postmenopausal women. Cochrane Database Syst Rev 1, CD004143, doi:10.1002/14651858.CD004143.pub5 (2017).

29. Dawson-Basoa, M. E. \& Gintzler, A. R. Estrogen and progesterone activate spinal kappa-opiate receptor analgesic mechanisms. Pain 64, 608615, doi:10.1016/0304-3959(96)87175-2 (1996).

30. Smith, Y. R. et al. Pronociceptive and antinociceptive effects of estradiol through endogenous opioid neurotransmission in women. $J$ Neurosci 26, 5777-5785, doi:10.1523/JNEUROSCI.5223-05.2006 (2006). 